\title{
Cultural Stereotypes and Linguistic Clichés: Their Usefulness in Intercultural Competency
}

\author{
Fabienne Baider, \\ University of Cyprus
}

\begin{abstract}
This paper addresses the selection of 'typical images' and linguistic clichés in language textbooks and attempts to evaluate their usefulness in teaching and learning intercultural competency. After definingcultural clichés and linguistic phrases, we draw on previous studies to point out their importance in learningand teaching a foreign language. We then present our own study, namely a survey of such culturally typical images and idioms as presented in popular textbooksused to teach French as a foreign language in our region (Cyprus). We then map out the criteria that might justify the editors' selection, and suggest modifications on the basis of our analysis of a selection of images, comments and phrases. Our suggestions are driven by research in sociolinguistics and intercultural pragmatics. We aim at promoting the most effective use of cultural clichés and idiomatic phrases in foreign language teaching as well as drawing attention to the potential danger of falling into counterproductive stereotyping.
\end{abstract}

\section{Introduction}

Cultural Awareness and Intercultural Competence are two of the new dimensions listed in the Common European Framework in language teaching. When talking about, describing, showing the Other, which any language textbook does, it seems difficult not to fall into stereotyping and reifying the Other--quite the opposite of what Interculturality aims toward. This study tackles this 'teaching impasse' on the basis of a thorough analysis of the most commonly used textbooks in teaching French as a foreign language, Festival and AlterEgo[1], and offers some answers to the following question: how can we make good use of cultural clichés and linguisticstereotypes, already found in those textbooks? Before presenting our data and methodology, we review theliterature on the topic. We then present our results and review possible criteria according to which the clichés have been chosen and can be taught. After suggesting other criteria based on sociolinguistic parameters, we also explain how a more effective selection can enhance as well the learning of such didactic material.

\section{Intercultural competency and linguistic stereotypes}

Intercultural competence includesknowing or being aware of cultural stereotypes and linguistic clichés as well as their correctusage. In fact, the CECR considers mastery of these two types of stereotypes the most significant indicator of intercultural competence. On the one hand one should know the 'typical' way of life and thinking of a specific culture in order to adapt when visiting the country or encountering their nationals; on the other hand, one should be able to recognize idiomatic phrases (semantic competence in intra-culturality) and know how to use them (pragmatic competence in inter-culturality).

\subsection{Nature and cognitive functions of cultural and linguistic clichés}

Both cultural stereotypes and linguistic phrases have been the focus of some previous research, especially through study of typical images (the French man with a béret and a baguette...), cultural clichés (the common idea that French people eat a lot but do not put on weight) and 'language stereotypes' (phrases, proverbs and situational clichés). Since language and thought are linked, stereotypes can be stereotypes of thought and / orlinguistic stereotypes. Indeed, authors often distinguish between the discursive cliché - a syntagm, expression, often taken from one speaker to another - and the stereotype as such - which involves meaning but not so much the expression [3], [12], [27].

Stereotypes of thought highlight beliefs, attitudes and prejudices which prevail in a given community. As cognitive schemata, they are typical of the human cognitive system, which assigns a set of characteristics to all members of a given social group. Thus they serve as a reference when assigning 
significance to observations and experiences in social interactions and cannot be underestimated when teaching or learning a language. In the opposite:

"They are mental structures, which simplify the complex stimuli from one's environment and facilitate their comprehension" [21].

They also reflect the natural tendency to make judgments based on our own reality when faced with a new reality, answering needs as varied as psychological comfort and the economy principle that operates in language evolution as well as the principle of differenciation. From a cognitive point of view, Amossy \& Herschberg [3] have defined them as the sum of the most saliant or the most relevant features in our daily reality or in the situational context. Quéré uses the concept of 'habitus' [8] to refer to the sum of values conveyed through clichés and language stereotypes.

To that effect, textbooks include social stereotypes and linguistic phrases since they are important as the more iconic dimension of culture and language.

\subsection{Usefulness of cultural and linguistic clichés in language teaching}

However, to acquire 'intercultural abilities' implies as wellbeing able to contextualise the knowledge in order to make sense for local contexts. This is precisely the most demanding aspect in teaching culture. When teaching a language, we have to strive to strike an uneasy balance between reifying a culture when presenting clichés and alerting students to the differences in the other culture in everyday living and thinking [4], [31], [33].

In the same way, language acquisition specialists have agreed over the years on the difficulties but also on the importance of semi-fixed phrases at any level of language learning [7], [25, [11]:

'The knowledge of and the ability to use prefabricated units are (thus) essential for the language learner; unfortunately, however, they also pose considerable difficulties, even for the advanced learner' [25].

Linguistic clichés not only convey an implicit cultural awareness, but they also exemplify the 'typical way' of expressing oneself as a native speaker. When used correctly, they can trigger recognition and acceptance within the target culture. They become the ideal way of sharing a language since using clichés is based on the 'déjà dit' (already said) and the 'déjà fait' (already done). Semprini [28] describes them as a liantcommun (a link and a commonplace type of thinking).
To that effect; today vocabularyis primarilytaught through the use of collocations, as thesehave the advantage of beingformedwithidentifiable and rather limited (therefore learnable) mechanisms [15]. Common, typical expressions used by the target culture and the target generation (a factor often underestimated) play an important role in the phatic function of communication [18]. Some examples of this phatic functions of linguistic clichés include(you must be kidding!), (unbelievable!), (come on!), etc... Many of these particles are used as discursive particles [27], [30] whose role is as important to the naturalness of the oral production as is the intonation in a language This linguistic material is part of the script or 'frame,' which is comprised in the language-culture, the habitus langagier et culturel.

\subsection{Previous studies}

Indeed previous investigations conducted in 2007-2008 [4], [32] on French textbooks denounced the role of many textbooks in discriminating against the most vulnerable members of the society and clinging to the habitus of the dominant culture. If the' target culture' is constructed within each chapter of the textbookfollowing organizing principles, it also answers power relations [8]. Some of the conclusions of these previous surveys were indeed the following:

- The increasing importance given to the image at the expense of text leads the student to establish only certain links that lead to stereotyping;

- The image of men and women continue to suffer differential treatment, less rewarding for women;

- The people of foreign origin represented are shown most often in demeaning situations and / or poverty;

- Disability is rarely mentioned;

- Seniors are often associated with representations related to the degeneration of the body without compensating such stereotypes with useful societal functions;

- The impasse is made on the topic of sexual orientation.

\section{Our own survey}

The two textbooks under study are cognizant of this (socio) linguistic material and of their role in language learning, since in theirprefaces they mention the importance of teaching such phrases.

\subsection{Data and methodology}

Both textbooks have been chosen since they are widely used in our university and in private schools in Cyprus. Alter Ego 2 is a French textbook for adult learners or older adolescents and aims tobring level A1 students to levels A2 and B1. Festival 2 is 
intended for advanced learners. Linguistic clichés are called 'sociolinguistic phrases' in Alter Ego (p.3), while in Festival they are called 'small words used in daily conversations or phrases typical of French speech' (p.3). From these definitions we would assume these two criteria, typicality and daily usage, to be the parameters used to select these sociolinguistic phrases. However this is not the case. To evaluate how cultural and language stereotypes are treated in these textbooks, we extracted the data presented in their chapters.

\section{Cultural stereotypes}

If both manualsaim at fulfillinglinguistic objectives (grammatical, lexical, phonetic), they also state aims belonging to a larger field: communicative and sociolinguistic skills, e.g., knowing a country and its people, discovering stereotypes, understanding travel information. According to the chapter themes, a cultural comment is made and each chapter ends by identifying typical portraits and typical behaviorin a French context. We focused our study on identifying ways these textbooks have been tackling racism and sexism, obvious objectives in intercultural studies.

\section{Linguistic clichés}

As for phrases theywere found to be peripheral to the main text.Listed expressions in both textbooksinclude short expressions such as disdonc! ('you say'!) and more elaborate expressions such as nevous en faites pas!('no need to worry!').

\subsection{Racism and sexism vs. Multiculturalism and parity?}

The textbooks under study have made great efforts towards multiculturalism. Festivalportrays many ethnic communities for instance and one of the leading couple is a mixed couple. As well, AlterEgo seems to challenge gender stereotypes, since two chapters (chap. 6 Lesson 2 and chap. 7 Lesson 3) have a section devoted to parity between men and women. However despite theselaudable efforts, a close look reveals discrepancies. If the mixed couple in Festival portrays a young man named Abdel, it is quite strange to see him preparing a 'quiche lorraine', a delicatessen made with bacon. In AlterEgothe chapter 6 starts a discussion on gender with anappalling article stating that men and women have different brains and different professions follow suit with successful women labeled as 'exceptional'. Our analysis shows as well that:

- An essentialist view of girls and boys is pervasive throughout the manual and goes against a policy of equality between the sexes. Pictures of girls (p 13 in curlers) andwomen (p. 14) relate to feelings whereas pictures of boys relate to sport, competition and technology (p. 140, p 142 and p. 152).

- Less valued social roles for women are still dominant: man are expertsor leaders whether in politics or medicine (p.72, p.50, and p.34) while women are foremost mothers or entertainers ( $p$. 72). ${ }^{1}$

Alterego seems also to be focused exclusively on France and the French society, tackling stereotypes about France and French people in chapter 3, without any reference to the Francophonie. One of the first stereotype well alive in this textbook is that French culture and French language is about France exclusively, not about Africa (where live more French speakers than in France) nor Canada (where the French culture is very much alive). The power of cultural and political dominance is alive and kicking, even in textbooks. Competence in interculturality is then reduced to the discovery of French culture by the' non - French' (Francophonespeakers but not French included). It is then very difficult to see opennessto others when the absence of reference to teachers and speakers outside France is so obvious. Linguistic clichés will also belong to the FrancoFrenchvariety.

\subsection{Linguistic phrases}

Indeed the Franco - French aspect could well be the only criteria of homogeneity in choosing the linguistic clichés to be learnt. Heterogeneity appears to characterize the choice of phrases. The collected data are all commonly used in France, but not necessarilyin other francophone countriesNot only do the datadiffergreatly between textbooks, they differ even within the same textbook, the presence of an expressionguided almost exclusively by its relevance to the theme of the chapter, or so it seems.From a sociolinguistic point of view, different registers are mixed without any indication of such a difference in usage in Festival 2.Indeed 'typical small words' include the colloquial ways of being in agreement (ouais! 'yeap!' ) and the formal way of agreeing (volontiers 'sure'). Nor does the frequencyof use for a given expression seem to have been a consistent parameter guiding the choice of expressions, since young adults will be less likely use Bien amicalement ('very best wishes') when signing off an SMS or an email (a likely means of communication) than signing Bises (+++) ou $A+$ ('see you later'), items which are not even listed.

\footnotetext{
${ }^{1}$ As well the choices of images reinforce power relations known in the world outside school, with handpickedfictional characters (no handicaps, no nonwhites, no poor, no elderly, etc.).
} 
From a syntactic point of view, the French phrases included range from fixed ones such as (endirect 'live') to semi-fixed ones (arriverd'une minute à l'autre to arrive any time soon') and to idiomatic expressions (donnersa langue au chat'to give up guessing'), the logic behind the choices being unclear. Moreover some suggestions can be rather difficultmorphosyntaxically or semantically for the targeted level A2, for instance, phrases such as n'en faire qu'àsa tête (to have a mind on its own). AlterEgo does warn its readership when some expressions are colloquial, but without giving the conversational context. Moreover, and again froma sociolinguistic point of view, the range in registersis quite formidable: from the very informal, almost impoliteçava pas non! (you must be joking!) (in Lesson 13) to the elaborate and formal cetteproposition esttrès controversée('this proposal is very controversial' in Lesson 14), with no indication of such a social distance.

From a pragmatic point of view, it also mixes phrases with different illocutionary force: some phrases can be used in a real situational context, for example, to congratulate (Bravo pour cette initiative 'well done for this initiative'in Lesson 2), while some seem to be more general, e.g., advice to find a job (demander le public visé 'you should ask for the targeted audience' in Lesson 9).

Given this heterogeneity, how can we teach such phrases so that the learners remember and use them?

\section{Recommendations}

In this section we suggest a combination of methodological approaches that may help students understand and learn linguistic clichés, as well as become better acquainted with the target culture: a sociolinguistic framework based on the Hymes model, syntactic and semantic patterns.

\subsection{A Sociolinguistic Approach}

Since linguistic clichés are called 'sociolinguistic phrases' in these textbooks, we would recommend that such phrases are always anchored in their typical situational context, following, for instance, the wellknown SPEAKING model [17]. In parallel, exercises should be provided so that students practiceusing each phrase; this will not onlyenhance their learning, but it will also guide teachers in explaining when use of such phrases is appropriate. As a matter of fact,in the textbooks under study, teachers are given no instruction or adviceon how to teach the clichés. This could be problematic, since not all teachers of French as a Foreign Language are likelyto know all the phrases -as a result they could find themselves in the embarrassing situation of not being able to explain the cliché. Furthermore, why does a textbook includethis learning material without providing the necessary tools to teach and learn it? Instructions are always provided for teaching grammar and vocabulary; moreover, this lack of instruction is in contradiction with the communicative approach which frames most textbooks.

\subsection{SyntacticModels}

We have observed the mixing of different syntactic patterns in the choice of linguistic clichés, whereby some are fixed and some are only semifixed. We believe that there must be some logic in the choice of phrases, and that students should be taught the frequently used 'syntactic patterns'first, so that they can build on this knowledge. Let's take the example of the syntactic pattern 'de... à' ('from ...to'). Students at the A2 level will be familiar with this simple syntactic pattern (since they would have learned, for instance, aller de Montréal à Toronto 'to go from Montreal to Toronto'at A1 level); we would then expand on this knowledge and present a phrase such as 'any minute' 'any time' etc. (an example given in one of the textbooks). We would make sure that students recognize the pattern and then expand on this to make them aware of other possibilities such as 'from one day to the other', etc. Learning a paradigmwould bemore interesting, more fun and more cost effective than learning just a random phrase. Other proposals given in Ortiz Alavrez [26] include asking students:

Ex. 1

To match a linguistic cliché with its semantic meaning (to face the music: to have to bear the consequences of one's actions);

Ex. 2

To find the semantic common link between phrases (topass away, to kick the bucket, etc.);

Ex. 3

To complete sentences with a semi-fixed phrase (She works very hard, stays up late for work and gets up early morning to get her assignments done. She burns the candle at both ends)

Ex. 4

To match half the phrase with its other half;

Ex. 5

To complete a multiple choice task focusing on phrases:

to frame someone:

a. to make a picture of someone

b. to prepare a trap for someone

c. to remember someone 
Ex. 6

To work from texts and have the students finding cultural stereotypes and linguistic phrases: a list is discussed students must find out whether the same phenomena exist in their own culture or language.

\subsection{Semantic Models}

Finally, we would make use of semantic patterns which underlie social practices 10]. For example, if we take the concept of 'work' no dictionary would write 'food' as a synonym;however, from a sociocultural point of view a salary is used first for payment of the basic necessities (lodging and food). Thus, there are linguistic clichés which illustrate via a 'shortcut' the connection between money and food: 'travaillermoins' is se serrer la ceinture (to work less means to tighten your belt); in the opposite, 'travailler plus' allows you to mettre du beurredans les épinards (to work more allows you to add butter to your spinach). Since working is about feeding yourself, the most iconic food in each culture will be the focus of linguistic cliches relating to work. As we know the French culture is famous for its bread (la baguette!),so to work is about gagner son pain ( to earn one's bread); rice is an iconic item inChinese culture (although in the northern part they eat more dough products), so for the Chineseto lose one's job is to lose one's bowl of rice; in the Dutch culture, the herringwill be used to represent work--to each one its herring (= to each one a job) [23].

A similar and basic need (to eat) is associated with the same process of thought (a metaphor)which takes shape in a language as a semi-fixed phrase. These common ways of thinking would also offer students in our multicultural classes an opportunity to share their culture with other students, and help them to discover sameness in diversity. To have the students working out similar phrases in their own culture is a wonderful way of sharing difference and similarities.These suggestions would enhance students' enjoyment in learning. Indeed, making students aware of similarities (whether at the cultural, syntactic, or semantic level) between their own culture-language and the target culturelanguage offers a certain degree of identification.To provide a few exercises (with answers for the teachers) would be useful to teachers who cannot know all these idiomatic phrases, since this kind of linguistic material evolves quickly and may well be different in the various French-speaking counties throughout the world.

\section{Conclusion}

Knowing cultural stereotypes and using linguistic clichés are important since such processes trigger recognition and acceptance within the target culture.
They become the ideal way of comparing and understanding cultures as well as sharing a language. Both offer a way to see the differences as they are encoded into the language-cultureas well as the sameness. While our study indicates that the textbooks we use in our region are aware of the importance of cultural clichés and such linguistic expressions, it has also identified a lack of consistency in their choicesand even some times a problematic way of confronting cultural stereotypes. Textbook material should then be reviewed by experts in sexism or racism for instance to evaluate the choices made by the authors of textbooks material: building bridges between the world of research and the commercial world of books is a solution to consider.For that matter collaboration between Gender Studies departments and textbook authors would be most fruitful. As well linguistic phrases should be introduced according to their sociolinguistic appropriateness, syntactic complexity and semantic sameness - an innovation that could be introduced when such textbooks are undergoing a revision. Here again a collaboration with the many sociolinguists and language acquisition specialists teachers who work on such matters could have extremely interesting and beneficial results. Texbooks are therefore a basis on which we can rely, but on which we certainly cannot 'rest': they are the basis for encouraging discussions and inventing provocative / challenging activities, which would result if not in an overall change inmentality, but at least in the development of empathy in relation to the other [20], [5], [19].

\section{References}

[1] Alter EgoA2, 2007, Hachette, Paris.

[2] Amossy R., A. Herschberg Pierrot, Stéréotype et clichés, Armand Colin, Paris, 1997.

[3]Amossy R., E. Rosen, Les discours du cliché, SEDES, 1982.

[4] Auger N., Constructions de l'interculturel dans les manuels de langue, coll. Proximités-Didactiques, Ed. modulaires européennes, Fernelmont, 2007.

[5] Bennet J. M, 'Turning frogs into interculturalists: A student-centered development approach to teaching intercultural competence', Crossing cultures, pp. 312-342, London, Routledge, 2004.

[6] Bolly C., 'La notion de compétence phraséologique', Les expressions figées en didactique des langues étrangères, Proximités-Didactiques, Ed. modulaires européennes, Fernelmont, pp. 33 - 53, 2007.

[7] Bolly C., Phraséologie et collocations. Approche sur corpus en français L1 et L2, P.I.E., Peter Lang, Bruxelles, 2011. 
[8]Bourdieu, P., La Noblesse d'état, Editions de Minuit, Paris, 1989.

[9] Cadre européen commun de référence pour les langues, Didier, Paris, 2005.

[10] Calvet J.-L., L'argot, PUF, Paris, 1994.

[11]Colson, J.-P., 'Les locutions verbales françaises et allemandes dans le dicours journalistique', Micro- et macrolèmes et leur figement discursif, Louvain - Paris, Peeters, pp. 173 - 199, 2000.

[12] Gadbois V., 'Cliché', Dictionnaire de la linguistique, Mounin G. (ed.), Paris, P.U.F., 1974.

[13] Galatanu O., "Pour une approche sémantico discursive du stéréotypage àl'interface de la sémantique théorique et del'analyse dudiscours", In Boyer Henri (ed.), Stéréotypage, stéréotypes : fonctionnements ordinaires et mises en scène, vol. 4, L'Harmattan, Paris, pp. 89-101, 2007.

[14] Gonzalez Rey I., ed., Les expressions figées en didactique des langues étrangères, Cortil-Wodon, EME, 2007.

[15] Grossman, F., Tutin, A., Les collocations : analyse et traitement, Amsterdam, De Werelt. 2003.

[16] Festival 2A1, Clé international, Paris.

[17] Hymes D., Foundations of Sociolinguistics: An Ethnographic Approach. Philadelphia: U of Pennsylvania, pp. 53-62, 1974.

[18] Jakobson R., 'Linguistics and Poetics', in T. Sebeoked., Style in Language, M.I.T. Press Cambridge, MA, pp. 350-377,1960.

[19] Koehn P. H., Rosenhau J. N., 'Transnational compétence in an emergent epoch', InternationalStudiesPerspectives 3 (2), pp. 105-27, 2002.

[20] Kramsch C., 'From communicative competence to symbolic competence', Modern Language Journal 90, pp. 249-252, 2006.

[21] Lehtonen, J., 'Cultural stereotypes and intercultural communication', The dynamics of language process, Tübingen, Gunter NarrVerlag,pp. 173-182, 1994

[22] Lipiansky M., 'La formation interculturelle consiste-telle à combattre les stéréotypes et les préjugés?' http://www.ofaj.org/paed/texte/stereofr/stereofr3.htm

[23] Marque-Pucheu C., 'Stéréotypes, économie de réflexion et de moyens : application aux Français et à la langue française', Didactique des langues: domaines et dénominations (éd. Mihai Dat), ABELL, Dijon, 2009, pp. 39-64.

[24] Martins-Baltar M., ed., La locution entre langues et usages, ENS éditions, Paris, 2002.
[25] Nesselhauf, N., 'How learner corpus analyses can contribute to language teaching: A study of support verb constructions', Corpora and Language Learners, Amsterdam, John Benjamins, pp. 109- 124, 2004.

[26] Ortiz Alvarez M.-L., 'As espresseõesidiomáticasnas aulas de ELE: umbicho de setecabeças?',Les expressions figées en didactique des langues étrangères, ProximitésDidactiques, Ed. modulaires européennes, Fernelmont, pp. 159- 181, 2007.

[27] Schapira C., Les stéréotypes en français : proverbes et autres formules, Paris, Ophrys, 1999.

[28] Semprini A., 'Sujet, interaction, mondes. Le lieu commun comme déixisinstituante', Protée 22(2),

Université du Québec à Chicoutimi, Canada, 1994.

[29] Solano Rodriguez A., ' El papel de la concienciafraseólogica en la enseñanza y aprendizaje de unalenguaextranjera', Les expressions figées en didactique des langues étrangères, E.M.E, Fernelmont, pp. 201 223, 2007.

[30] Vincent D., Les ponctuants de la langueet autres mots du discours, Nuit blanche, Québec, 1993.

[31] Young T., Sercombe P., Communication, discourses and interculturality, Language and Intercultural Communication 10(3),Routledge, U.K. pp. 181-188, 2010.

[32] Wagner, A-L., P. Tisserant, Stéréotypes et manuels scolaires. Université Paul Verlaine de Metz: FNRS, Education \& Formation. 2010.

[33] Woodin J., 'Cultural categorisation: what can we learn from practice?', Language and Intercultural Communication10 (3), Routledge, pp. 225-242, 2010. 